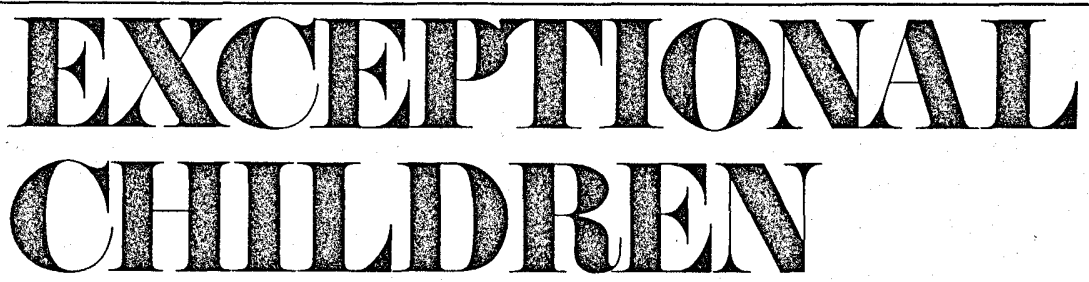

\title{
DEVELOPING INSTRUCTIONAL MATERIALS FOR EMOTIONALLY DISTURBED CHILDREN
}

\section{INSTRUCTIONAL MATERIALS FOR TEACHING THE EMOTIONALLY DISTURBED}

\section{By Don C. McNeil}

Although instructional materials are as old as education itself, there has probably never been a time when they have assumed so much importance in overall strategies of educational planning; their significance is highlighted both by the recent rapid proliferation of materials and the considerable money and energy invested by publishing companies in their developrent and marketing. Nor has special education been slow to recognize this importance, as may be attested to by the concern for adequate media and materials in special classes, to the point where any special classroom not having at least a basic complement of projection and sound equipment is considered a wasteland indeed. In fact, expansion has been so heady that some faint souls have expressed concern lest materials replace, or at least diminish, the classroom teacher; conversely, some workers in the field have suggested programming the teacher to act like a machine, in the sense of presenting stimuli and reinforcing behavior.

Much of this growth has been characterized by a rather ad hoc response to perceived needs, rather than any consistent developmental rationale. Indeed, the development of many of our materials is probably much more closely tied to general technological advances in the communication fields than to any theoretical or factual increase in our knowledge concerning human growth and development. Some optimists feel that the dawn of an era of educational technology is now upon us, which will catapult education into the space age as an equal partner in producing and consuming esoteric technical devices. Certainly, the potential effects of increasingly sophisticated hardware have been sensed by many, but little effort has gone into assessing the way in which materials fit into the overall scheme of the teacher-learning process, nor have there been consistent efforts made to relate content and structure to current physchological and educational models of behavior and learning. There are certainly exceptions to this; witness the derivation of the teaching machine from a consistent behavioral model, although even here there is little clarity concerning just what it is

1. Don C. McNeil is Coordinator of Programs in the Area of the Emotionally Disturbed at the University of Texas.

(C) Love Publishing Company 1969 
that will be done with the child before and after his programmed experience. This is perhaps most typical of the state of instructional materials today, which are being produced rapidly and in many different areas, sometimes claiming exaggerated applicability to multiple classes of educational problems, but seldom demonstrating in any obvious way how they might be expected to fit into any larger educational pattern. The fact that we presently have no adequate theory of teaching nor, for that matter, any comprehensive explanation for how children accomplish the variety of different learning tasks with which they are presented in the classroom, presents a formidable obstacle to any thoughtful integration of the uses and constraints of these numerous materials.

\section{SOME APPROACHES TO EDUCATIONAL INTERVENTIONS}

This state of affairs is perhaps even more relevant in the area of programming educational experiences for emotionally disturbed children. There are currently several easily distinguishable approaches toward provid-

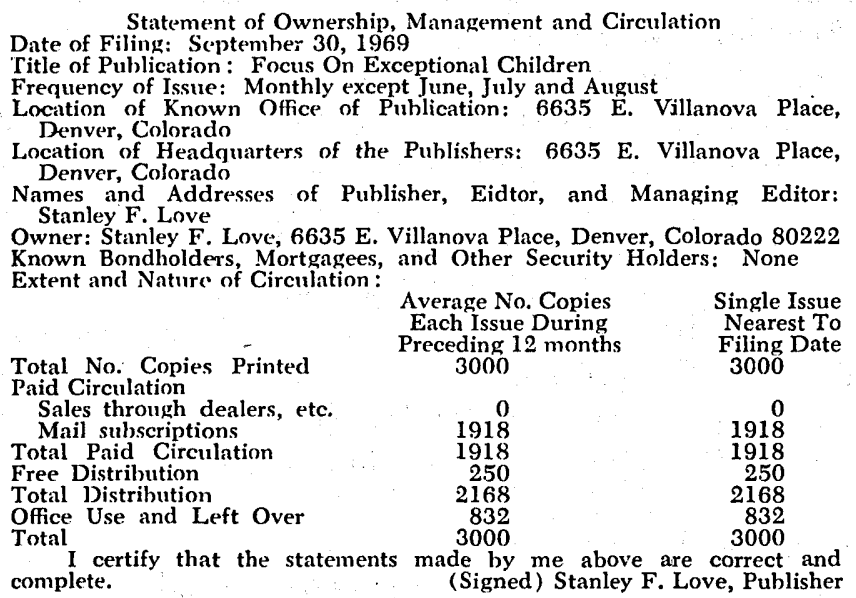

FOCUS ON EXCEPTIONAL CHILDREN is published monthly except June, July, and August as a service to those concerned with mentally retarded and emotionally disturbed children. Subscriptions rates, $\$ 9.50$ per year. Copyright 1969 Love Publishing Company. All rights reserved. Reproduction in whole or part without written permission is prohibited. Printed in the United States of America. Second class postage is paid at Denver, Colorado.

Executive and Editorial Offices
6635 East Villanova Place
Denver, Colorado 80222
Telephone (303) $757-2579$

\section{EDITOR}

Dr. Edward L. Meyen

The University of Iowa

Washington Report

Valeita J. Naegle ing educational interventions for these children, with considerable diversity of practice both between and within approaches. Proponents of each method have attempted to operationalize the nature of their interventions according to assumptions concerning the genesis of pathology and concomitant goals for health or adaptive behavior. However, development and utilization of instructional materials have not necessarily followed from these assumptions, making it difficult to design and evaluate differential contributions. For example, those practitioners who derive their interventions from learning theory tend to emphasize specific behavioral objectives in the careful planning of the classroom structure and reward contingencies. Often the materials available in these classrooms are impressive, but little attention has been given, in a specific way, to the manner in which different materials might contribute to structure for an individual child. In the same way, it is often assumed that discovering the correctness of his response is rewarding to a child while, at the other extreme, it has been suggested that teaching machines be equipped with pyrotechnic displays resembling the scoreboard at the Astrodome after a home run has been hit, in order to encourage children in their education endeavors: Between these extremes, with the exception of the ubiquitous " $M$ and $\mathrm{M}$," little attention has been given to the possibility of programming differentially flexible rewards into programmed sets.

Another common approach to working with disturbed children tends to focus more on psychodynamic aspects of classroom interactions between children and teacher. In this setting, relatively more emphasis may be placed on the child's self concept, his ability to relate positively with his peers, and his growth in more accurate perceptions of the nature of social situation in which he is involved. Seldom, however, are these goals reflected in the content or structure of the materials to which he is exposed. Indeed, many times classrooms espousing quite different intervention approaches may have nearly identical sets of instructional materials. This is probably due chiefly to the fact that this aspect of the teaching-learning situation has not generally been planned as carefully into the total fabric of strategies as have other dimensions.

\section{MODIFICATION OF EXISTING MATERIALS}

Another characteristic of this area of special education has been a strong tendency to focus on the adaptation of existing special or regular instructional materials, rather than the development of programs specifically designed for emotionally disturbed children. This may well be due to the extensive heterogeneity of the group of children we 
call "disturbed" than of any predisposition of practitioners, and it is conceivably the most appropriate strategy at this time. However, this lack of specificity in the creation of materials for different groups of disturbed children has perhaps inhibited the growth of knowledge concerning ways of handling information, and the impact of this information, on certain kinds of children. In a more general way, the same statement may be made concerning curricula for disturbed children, which in general consists of slightly modified models of existing public school practices. Again, this approach may have its strengths, but is scarcely innovative and does not enhance the development of more specific instructional strategies.

However, in view of the extreme heterogeneity of groups of children which may be labeled "emotionally disturbed," it is valid to question the feasibility of planning special curricula and materials, if these will not solve the problem of individual differences with more effectiveness than programs already existing. Planning for the "average" emotionally disturbed child will produce little better results than producing all trousers to fit the average American male, as many Army recruits could testify. On the other hand, it should be possible to apply our knowledge of normal and deviant child development to this problem in order to derive at least a rough set of characteristics that meet two criteria: (1) they have been shown to be educationally and developmentally important, i.e., children demonstrating these characteristics may be expected to experience increasing difficulty in using school as a positive growth experience, and (2) the probability of these characteristics occurring in any group of children labeled emotionally disturbed is significantly higher than one would expect. Utilizing these criteria, there would seem to be a number of characteristics which might help in developing more specific educational strategies and tactics which would be directly represented in the development of instructional materials.

The possibilities for the direction of programming in this area are numerous, and of course would depend partially on the goals and theoretical biases of the programmer. For example, motivation is frequently mentioned as a problem area by teachers of disturbed children. The interest value of materials is often exploited as much as possible. Catching a child's attention is a vital and necessary condition for learning to take place, but even on the interest level our evaluation has been exceedingly general. Exactly how do we handle the problem of overor under-stimulation? When is it important for a child to respond, and how often? From the child's point of view, when is an interest to be considered a healthy manifestation of growth, and when might we be in danger of exploiting a preoccupation which is more likely to be pathological? Beyond this, what are the possibilities for programming materials and media to elicit and maintain longer sequences of goal-directed behavior, exploration, etc.

Another frequently noted characteristic of these children is anxiety, which is often high enough to effectively inhibit learning. Quay has pointed out the potential benefits in applying the extensive research on the effects of anxiety on learning to differential programming for disturbed children (1963). Furthemore, is it possible to design the content and form of presentation of materials in such a way as to reduce or allay anxiety, and, if so, when should this be done? There is a related problem of neutralization of material which may be particularly anxiety-arousing to certain children; should this material be completely avoided, could it be imbedded in a diferent context, or presented as successive approximations along with more benign stimuli?

A similar characteristic which may be found in many disturbed children involves impulse control, and again the same general questions may be asked: "How does one avoid or handle materials which may prove to be above a certain child's control threshold?" Is there a way to sequence materials and design hardware which may help to create a life space for the child which will not make it any more difficult, and may enhance, the handling of impulses? This would be similar to much of the work done in educational programming for minimally brain-injured or hyperactive children, but might be expanded considerably with more sophisticated hardware available, and also in planning ways in which to avoid physically segregating the child from the rest of the classroom group. The possibility of games which might provide minimal social interaction under controlled conditions, or enhance cooperation between children, or child and teacher, might be considered. The unique nature of games may present unusual opportunities to include important content and, at the same time, structure behavior through the use of certain materials; this could even conceivably be done using the spatial dimensions of an entire classroom or school, much as Monopoly does on a tabletop scale. Since learning within the context of a group appears to be such an important aspect of a normal child's educational development, it would seem to be particularly important to devise ways to provide necessary structure without use of consistent isolation. At the same time, hyperactive children often appear to require frequent opportunities for large 
muscle movement and expression of energy; this might be programmed more naturally into many facets of classroom experience. For example, if we are going to use a teaching machine with a child like this, we might design one which requires considerable motoric response to change the frame: a large wheel to turn rather than a well-oiled slide.

The adaptation of materials for use with disturbed children has also largely inhibited the development of content designed to stimulate particular emotional or social processes in these children. Ojemann and others have devised materials designed to lead to interpretations of behavior which are causal rather than superficial in nature; these projects tend to demonstrate the efficacy of this sort of approach in promoting mental health within a public school setting (Ojemann, 1962). Likewise, a number of reading series have deliberately programmed content which will be more personally meaningful to certain groups. One might speculate that this sort of effort, focused on the needs of particular groups of disturbed children, might have considerable potential in supplementing and extending the teacher's efforts in this direction.

The attempts to provide a variety of school experiences designed to stimulate growth of important ego processes are also relevant here. Hollister's notion of "stren," i.e. a specific strengthening and potentiating experience, might help give coherence to strategies for developing special instructional materials (Hollister, 1968). All of this work implies that carefully designed learning and socialization experiences have considerable potential for strengthening those ego processes which may well represent areas of considerable developmental need in disturbed children. The assumption is stressed here that if a child can be helped to find success in his school experiences, to develop skills that he can utilize with pride, and to become involved in the life of his classroom and, vicariously, in that of the world, we can characterize this as being therapeutic in the best sense.

\section{DESIGN OF MATERIALS FOR TEACHING}

\section{THE EMOTIONALLY DISTURBED}

These illustrations are intended to point out the possible validity of designing materials specifically for use with disturbed children. As I indicated earlier, utilization of materials for these children presently involves modification of existing regular or special resources. This is not to imply that no materials be admitted to use with disturbed children unless they are specially designed; many materials now available are most useful and relevant to the needs of a good many children. What is perhaps more important is that the teacher have a full range of different kinds of materials available in her bag of tricks, with immediate access for whatever contingency may arise within the learning situation, and that these materials be as problem-specific as possible. However, attempting to specify rationales appropriate to the development of special materials might well prove helpful in the modification and utilization of materials designed for other children. That is, if one wishes to modify an instructional reading program originally designed for slow-learners, to use with a group of hyperactive boys, can we use a strategy which may prove more efficient and give us more information than trial-and-error changes?

In most special educational settings, materials are not used in nearly so structured a manner; basic resources such as books and workbooks may represent the most structured and frequently used end of the continuum, while other materials resemble a good smorgasbord. The major criteria for utilization usually include at least the areas of enrichment, interest, and achievement flexibility. Enrichment is often seen as an important attribute of instructional materials; by the use of various written, visual, or sound materials a child may vicariously experience many different aspects of the world outside the classroom. Of special importance here is the fact that the student is not restricted by poor reading skills in making use of films or recorded content.

Similar to this dimension is that of interest to provide increased motivation and attention. High interest, low vocabulary readers would be an example of this strategy. Another closely related dimension is flexibility; given an appropriate range of materials, the teacher can quickly put her hands on something which will both interest the child and at the same time provide materials closely related to his level of skill functioning. This diversity of materials can be of inestimable value in meeting the multiplicity of education and psychological needs found in most special classes. The same would apply, of course, for the disturbed child in a regular classroom. Still another purpose would be provision of a model of a concept on the motoric, perceptual, or symbolic level, which may allow a student to more easily grasp the essence of an idea e.g., anatomical models, schematic diagrams, etc.

This is of course not intended to be an exhaustive review of criteria used in selecting and utilizing materials, but the dimensions of enrichment, interest, achievement flexibility, and concept modeling enter heavily into most decisions regarding classroom resources. It may well be, at the operational level, that they are the most appropriate. However, for the development of materials 
and the design of adequate media, these criteria appear excessively general. They do not provide a framework with enough specificity to plan well-defined goals or to determine the interaction effects of materials directed at one aspect of a child's need with other psychological processes. This in turn makes it difficult to evaluate materials and also, when considering a theory of teaching, to determine the most appropriate ways in which a teacher uses certain resources in order to effect particular changes in children.

\section{A MODEL FOR THE DEVELOPMENT OF INSTRUCTIONAL MATERIALS}

A model for the development of instructional materials for emotionally disturbed children could conceivably take many forms; the one presented here is intended only to illustrate the complexities involved and the need for a framework illustrating the range of possibilities and many potential interrelationships between variables. It represents a broad-based strategy which the developer of materials must keep in mind when planning the tactics and content of his proposed resources, while at the same time forcing him to decide what it is that is being prepared, how it is to be optimally presented, and who it is being prepared for.

\section{Description of Model}

The following diagram is not technically a model, but is for the purpose of representing the choice points involved in establishing a strategy for the development and evaluation of instructional materials. The first box, in Column A, specifies the theoretical assumptions and related goals which are established for any intervention project. For example, is the assumption made that all maladaptive behavior is learned in the sense of an operant model; are we concerned with changes in the child's self concept, the quality of his relationships with others, etc? Following from these assumptions, decisions are usually made regarding strategies to be used, e.g., operant technology, concentration on relationships, etc. Given this, the next steps involve relating these goals to Columns B, C, and D. Column D, Organismic Variables, subsumes whatever educational and psychological assessments which may have been carried out. These characteristics might represent status information, as in the case of developmental level or present anxiety; however, they also imply a change dimension related to the goals in Column A. For example, we might focus on a high level of anxiety with the goal of reducing it to a point where the child can more effectively accomplish certain academic goals. The point is that these goals are specified and related to previous assumptions; the goals, of course, should be stated in such a way as to allow for evaluation and later corrections in our interventions.

It is here that the consideration of cognitive development and how children learn in the most effective way takes place. Actually, we know relatively little concerning the functioning of basic psychological processes in children who may have particular emotional problems. For example, it is often assumed that children with particular difficulties in learning have some sort of distortion in their perceptual system, but the nature of the process that is operating is often relatively unclear. If the child consistently confuses different letters, we might assume that his problem is one

\section{A SCHEMATIC DIAGRAM FOR USE IN DEVELOPING, EVALUATING, AND UTILIZING \\ INSTRUCTIONAL MATERIALS WITH EMOTIONALLY DISTURBED CHILDREN.}

\section{Teacher - Programmer}

A.

\section{Theoretical assumptions} and behavioral goals
1. Nature of pathology
2. Causes of pathology
3. Intervention goals Etc.

B.

Content variables
1. Purposes
a. Information- enrichment
b. Models of concepts
c. Identication, dramatization, etc.
2. Focus
a. Predisposition
b. Concept learning, structure
c. Socialization

3. Strategies

a. Sequencing

b. Reinforcement, Etc. c.

Media characteristics

1. Visual

a. Picture

b. Word

2. Auditory

a. Word

b. Sounds

3. Multi-media

4. Control

a. Learner

b. Teacher

c. Programmer

5. Duration
D.

Organismic variables

1. Developmental level

2. Learning deficits

3. Anxiety

4. Behavioral

characteristics

5. Impulse control

6. Attitudes

7. Self-concept

8. Reinforcement history, Etc.
E. Output, Goals \&
evaluation

1. Achievement goals

2. Behavioral goals

3. Developmental goals 
of discrimination. However, what information does this tag yield in terms of the most appropriate instructional approach; do we have him practice on discrimininations between letters, between squares and circles, or is there some even more basic problem which must be dealt with first? Here the question really involves the validity of the relationship between diagnostic labels we may choose to use and the interventions which follow these labels; do they really help? While much research is still required to resolve these kinds of issues, systematic attention to them as we present different kinds of materials, as well as careful evaluation in the classroom, may be most useful in providing increased clarity. The point here is to pay more detailed attention to these learning variables in the child, and not to assume that because he demonstrates some difficulty in the use of perceptual skills that a program labelled "perceptual training" will necessarily do the job. We may be missing a number of other educational needs in the area of perception and other psychological processes if our focus is restricted in this manner.

The same point, of course, could be made in reference to a variety of psychological dimensions; concept formation, problem-solving abilities, etc. The child's self concept might be of crucial importance to the teacher, both in terms of the satisfactions inherent in skill acquisition and relevant feelings about the self and school. These variables are important in deciding what the child is ready for, i.e., what kinds of academic expectations can he presently be expected to tolerate, and also the content and form of the materials which we present to him.

With goals and assessment of organismic variables specified, Columns B and C relate to the actual development of materials and strategies in terms of their utilization. Column B, Content Variables, would logically be the next step in our consideration. Here, the programmer would concern himself with at least three dimensions: (1) what is the educational purpose of presenting certain content to this particular group of children? Do we wish to provide enrichment concerning the lives of people inhabiting the African continent? Do we want to provide a model of the concept of photosynthesis? If so, will the most effective presentation be in perceptual or symbolic terms? To make this decision we must refer to Column D, Organismic Variables. (2) What is the focus of the proposed materials? Is the main concern with the predisposition of the child to approach an interesting learning situation; are we more concerned with concept attainment or the acquisition of certain skills; or are we more interested in socialization aspects of the child's behavior? Of course, in any situation we might choose to focus on more than one dimension. (3) Finally, what strategies must be planned into the utilization of these materials? Here one must decide how the stimuli are to be sequenced; what kinds of reinforcements may be considered, contingent on what behaviors, etc.

With all these factors in mind (From Columns A, B, and D), the next step is to consider the most effective mode of presentation. Our choice might be to use books, workbooks, movies, games, tapes, teaching machines, etc. The important point here is to make the decision on the basis of stated goals and programming variables, and not on the basis of any current fascination with gadgetry. What is the best sensory input, or combination of inputs, for the child in question? Are there inherent qualities in certain media which would tend to predispose some children to approaching and maintaining goal directed behavior? It may well be that a computer-assisted instruction device might be best for teaching certain concepts, or a teaching machine for arithmetical skills, while a movie or a well-prepared book might serve enrichment or interest purposes much more appropriately and economically. Without assessing the range of variables included in the diagram, it is difficult to makes these decisions in the most effective way.

Once the materials are prepared and put into operation, Column $\mathrm{E}$ becomes the major focus. Here we can specify different goal domains and institute evaluation procedures not only to demonstrate the efficacy of our materials, but hopefully to provide information which will allow us to improve them. Here it is important to realize that there are several levels of evaluation, at least two of which should be employed. The first is the more typical: a general evaluation after a complete temporal sequence, with perhaps an achievement score serving as a dependent variable. For example, we might collect pre-and post-information on a child's arithmetic or reading achievement after six weeks of exposure to a certain program. The other level, which is much less common in the development of instructional materials, involves a detailed analysis of the process of learning as a child interacts with a particular set of materials. This would be similar to Suppes' work on the development of mathematics curricula, where he found, for example, that it is easier to solve " $3+X=8$ " than " $X+3=8$ " (Suppes, 1968). Evaluation at this level would hopefully provide much more specific information to feed back in order to make changes or corrections in the previous steps. For example, we might find that the auditory component of a program is redundant for some children, necessary for others. For some children, on-task behavior might be enhanced considerably by provision of a particular set of 
materials, although their skill level might not increase correspondingly; the task then becomes to analyze components of the program in order to retain aspects which stimulate interest in goal-directed activity, while changing the program to promote skill acquisition.

\section{Selection of Materials}

While designed primarily to guide the development of instructional materials, it may well be that this sort of schema would also be useful in the selection and modification of commercially available resources for use with disturbed children. In the selection of materials, it would seem highly important to consider theoretical assumptions and intervention goals, in an effort to choose those which will most appropriately fit the design of a particular classroom. Within this framework, studies which would assess functional needs of different groups of children, while at the same time evaluating the effectiveness of different instructional programs, should increase the specificity with which the teacher can plan an effective learning program.

\section{The Teacher As Innovator}

Although this discussion has been devoted to the development and use of instructional materials, to neglect consideration of the teacher who will be using these materials is analogous to listing safety improvements in automobiles without considering the driver. No matter how prescribed and structured the learning setting, it is obvious that the teacher must always serve as the innovative mediator between educational resources and the child. The essence of the effectiveness of any materials, no matter how well developed, occurs in the actual confrontation with children. In making a decision regarding what will be presented, and adopting an approach toward the child, the teacher must utilize all her educational skills in assessing readiness, what it is that will be most productive for the child to learn, and how he can best learn it at this time. Concurrently, if the teacher has developed the kind of empathy which allows him to understand in some fashion the child's way of perceiving his environment, he will be able to predict how the child will see this particular assignment or set of materials. Will he see it as just another hated arithmetic book, no matter how colorful its cover and illustrations? Will this gleaming teaching machine be seen as something impossibly difficult and too complex to ever master? Or will it be seen as an invitation to learn, to manipulate, to work on, and so forth. This is where the clinical skill of teaching, involving here empathy and the ability to both support and motivate a child, is of paramount importance.
Many teachers probably intuitively use a rationale such as the one presented here in selecting and guiding the use of instructional materials. Certainly the files of many of these teachers are literally bulging with self-made materials and multitudes of dittos. If these could be gathered together, they would represent a veritable goldmine of ideas for the development of new materials. However, time limitations make it very difficult for most people to develop or evaluate materials as effectively as they would like. Therefore, the development or modification of materials with demonstrated validity in stimulating behavioral change and academic growth will merely increase the effective range of the total resources which the teacher can bring to bear on the many and complex problems which he faces each day in a classroom setting.

Finally, in relation to testing out various programs, there is one other important consideration to keep in mind. Both in terms of formal incidence studies and the observations of most people who live in schools, the kinds of disturbing children we are discussing represent a problem of considerable scope. It is becoming increasingly clear that we do not want to segregate all these children. in special classrooms for a number of reasons; beyond this, it is clearly an impossibility in terms of economics and available personnel. Therefore, it seems essential that in our schemes for developing and using instructional materials, we give due consideration to those resources which can be adapted to special needs within a regular classroom.

\section{BIBLIOGRAPHY}

Bruner, J. S. A Theory of Instruction. Belknap Press, Harvard University Press, 1966.

Cowen, E. L.; Gardner, E. A.; and Zax, M. Emergent Approaches to Mental Health Problems. New York: Appleton, Century, Crofts, 1967.

Dale, E. Instructional Resources, in: The Changing American School. 65th Yearbook, The National Society for the Study of Education, Goodlad, J. (Ed.), NSSE, University of Chicago Press, Chicago, 1966.

Flannagan, J. C. The Uses of Educational Evaluation in the Development of Programs, Courses, Instructional Materials and Equipment, Instructional and Learning procedures, and Administrative Arrangements, Chapter 10 in: Educational Evaluation: New Roles, New Means. 68th Yearbook of the National Society for the Study of Education, Tyler, R. (Ed.), University of Chicago Press, 1969.

Gage, N. L. Theories of Teaching, Chapter 11 in: Theories of Learning and Instruction, 63rd Yearbook of the National Society for the Study of Education, Hilgard, E. R. (Ed.), 1964, University of Chicago Press.

Hollister, W. The Concepts of "strens" in Curriculum Development, in: Bower, E. and Hollister, W. (Eds.), Behavioral Science Frontiers in Education, 1968.

Ojemann, R. H. Investigations on the Effects of Teaching and Understanding An Appreciation of Behavior Dynamics, Chapter 17 in: Kaplan, C. (Ed.), Prevention of Mental Disorders in Children, New York: Basic Books, 1961. 
Quay, H. C. "Some Basic Considerations in the Education of Emotionally Disturbed Children," Exceptional Child, 30:27-31, September, 1963.

Spear, B. F. "Teaching Machines," Scientific American, November, 1961.

Suppers, P. Learning About Learning. U. S. Office of Education Monograph, 1968.

Taylor, C. W. and Williams, F. E. Instructional Media and Creativity, New York: John Wiley and Sons, Inc., 1966.

Whelan, R. J. and Haring, N. G. "Modification and Maintenance of Behavior Through Systematic Application of Consequences," Exceptional Child 32:5, January, 1966.

\section{ISSUES}

\section{E TRENDS}

Is the process of developing curriculum for handicapped children significantly different from the procedures involved in structuring curriculum for children enrolled in the regular program? While the content may differ for certain categories of exceptional children, it would be reasonable to suggest that the process of reaching curriculum decision is basically similar. Yet in practice it appears that curriculum consultants, specialists, and coordinators are frequently not involved in curriculum planning for special education programs. It is the teacher who falls heir to the responsibility for making curriculum decisions. While she may be capable of instructional decisions as they relate to her own class, for the most part teachers are not prepared to do a job which should be handled by a curriculum specialist.

The investment made in general education on curriculum development, revisions, and innovation is evidence of the complexity of the process. Yet in many areas of special education, educators proceed as if they are equipped to independently undertake the development of curriculum without the aid of those trained in the process. Or at least they have been unable to involve those persons possessing such skills. What is represented as curriculum in special classes for the retarded in essence is not the product of curriculum specialists, but rather it is a result of an attempt by special educators to independently structure an educational program. Should the special educator happen to be skilled in curriculum development, the risks are lessened. However, the typical director or supervisor is not trained in the area of curriculum.

It would be naive to suggest that the special educator need only to ask for assistance in order to involve the curriculum specialist from his district. What is probably needed is more involvement of curriculum specialists in research and in teacher training dealing with handicapped children.

It may be that the criticism being leveled at the special class concept is aimed in the wrong direction. The deficiency of the system as practiced might not be inherent in the concept but result from the process typically followed in establishing curriculum within the structure of the special class concept. One could certainly build a case to support the point of view that we have historically failed to invest sufficiently in curriculum development for the mentally retarded. Because of this, our expectations in terms of the progress of children in special classes for the mentally retarded may need to be modified.

If the special class teacher is to be freed of the responsibility which accompanies curriculum development and allowed to concentrate her efforts on the teaching process then some changes are in order. Such changes should include more interaction among special educators and curriculum specialists at the elementary level, a greater investment in curriculum research, and a broadening of the curriculum specialist's role at the local level to include a direct relationship to the special education instructional program. A point of departure might be to review the certification requirements for the administrative and supervisory positions at the local level. Since persons holding these positions represent a major source of influence on the special education instructional program, it certainly seems that they should be skilled in the process of curriculum development.

The Issues column is intended to serve as a forum for discussion of current concerns as they relate to programming for the mentally retarded and the emotionally disturbed. Persons uishing to contribute to this column are encouraged to do so. The statement should not exceed 800 words. Response to issues are also welcome. Both should be submitted to the editor.

\section{FREEDOM OF SPEECH-EVEN FOR THE MENTALLY RETARDED}

\section{Paul M. Retish ${ }^{1}$}

"What do you do on your first date?" "Why do others in school walk away from me?" "Why do others call me names?" These are questions commonly asked by the

1. Paul M. Retish is a member of the faculty of the Division of Special Education of The University of Iowa. 
teenager labeled "retarded." However, another teenager is ill-equipped to answer these questions, and unfortunate situations may result. Take, for instance, the 15-yearold boy who disappeared from home and school for four days and was found living with a 26-year-old woman because she was nice to him and taught him about the changes that were occurring to him. He was, of course, dismissed from school until his conduct improved. This boy came from a home where the parents had too many problems and no known resource to help them.

The example is extreme, yet it typifies the lack of resources these young adults have to draw upon when trying to understand themselves in relation to their environment. With maturing there is more socialization, and a teenager notices the differences which exist between himself and others. His body, his thoughts, and his labeled differences raise many questions, and his need to understand is also great. He begins searching for a situation in which he feels comfortable, and which will provide satisfactory answers to the questions that disturb him. But as of yet there is no real help available.

The lack of adequate communication skills contributes to the dilemma of the retarded youth who seeks a relationship which allows him to express his concerns without the risk of ridicule. It does not mean that he has no desire to express himself or does it mean that he does not have something to say. Rather, it suggests that he encounters difficulty in transforming feelings from thoughts to verbal expression. He needs a confidant, and his peers fall short of meeting this need. This type of youth represents the majority of educable mentally retarded students in special classes. While they require academic training, their need to express themselves and to have their concerns responded to with the seriousness they warrant is very real. The "freedom of speech" privilege promulgated in our society is greatly restricted for the intellectually limited individual. To experience "freedom of speech" necessitates an audience. Who listens to the retarded? Almost no one. Consequently, they become inhibited in seeking answers to their questions.

The special class teacher capable of creating an atmosphere of "free speech" and willing to invest instructional time in meaningful dialogue with the retarded youth may in the long run come closest to changing the behavior of the retarded individual. Teachers should be more than dispensers of facts or groomers of personalities. They must serve as counsellors and friends as well as surrogate parents. If the classroom activities build relationships which stimulate "free speech," the chances of the retarded youth generalizing this reinforcement to other social situations are greatly enhanced.

The responsibility to foster free speech falls to the school partly by default but also because the classroom setting represents an opportunity to develop the communication skills of the mentally retarded. Freedom of speech becomes a methodology in the creation of an atmosphere where the retarded child can learn. It becomes a modality that can be exercised as long as the atmosphere is there and the lines of communication are open. The teacher must be fully aware of the implications of this approach for the overall development and adjustment of the mentally retarded.

If free speech is to prevail in the special class as a method of instruction, the entire faculty must understand the teacher's rationale for this method. Otherwise, the casual observations by colleagues and administrators might result in an interpretation that the process is merely a substitution of conversation for teaching. Other teachers who work with the special class pupils must also be cognizant of the reason for establishing close relationships with these pupils and be prepared for engaging in similar discussions through their relationships with the students. Anxieties may arise regarding what and how such discussions should proceed. Consequently, understanding of the goals and rationale for the program are necessary on the part of the faculty.

The end product of special education programs for the retarded should be reflected in individuals characterized by the ability to assume a self-sufficient role in society and capable of establishing interpersonal relationships which help them fulfill their needs as social beings. The emphasis on free speech, the stimulation of self-expression on the part of the learner, and the establishment of true rapport between teacher and pupil may well be the difference between special and regular education for the retarded. In contrast to asking the retarded youth to learn the language of a middle-class, college-trained teacher, the teacher must learn the language of her pupils if she is to understand them and to meaningfully communicate with them. There is no place for the teacher. to say, "I cannot talk to you about this problem." She must exercise a free hand, and conduct any discussion of problems that might arise in the classroom. Teacher and student must feel confident that they can at least attempt to resolve any problems which arise.

The mentally retarded youth must develop sufficient trust in his peers and teacher to permit him to discuss problems which concern him. Developing such an atmosphere is no small undertaking, but it is a first step for a teenager who is trying to understand his world and the demands it makes of him. 


\section{INTERDISCIPLINARY CLINICAL PRACTICE:} A Training Model

\section{By Alexander L. Britton and Robert J. Swan ${ }^{1}$}

Recognizing the need for school psychologists and special education teachers to improve interdisciplinary communications and develop mutual respect, the Pupil Personnel and Special Education Programs at California State College at Long Beach have developed a cooperatively sponsored clinic for children with emotional disturbances, neurological impairments, and/or learning disabilities. Aware of the benefits derived from practicum experiences on the part of the students, faculty members provide opportunities for trainees in school psychology and special education to work cooperatively in the clinic setting.

A special education course sequence in the area of learning disabilities has been developed encompassing concepts in behavior modification, prescriptive education, and behavioral objectives. Master of Science candidates in Special Education are required to enroll in the following:

Education of Children with Learning Disabilities (3)

Education Remediation (3-3)

Special Education Practicum (3-3)

School psychology students are required to engage in clinic practicum experience concurrent with an advanced training course in Clinic Practice in Educational Remediation (3).

School psychology students have the responsibility for diagnosis, assessment, and evaluation of incoming children. They are responsible for the writing of a clinical report presenting strengths, weaknesses, and educational needs of each subject. The current trend in school psychology substantiates the need for the school psychologist to be able to communicate and demonstrate to teachers the assessed behavioral objectives and teaching strategies indicated for individual exceptional children. Hence, psychology trainees are required to write a prescription stating specific behavioral objectives, particular strategies and teaching activities, and evaluative procedures for each child admitted to the clinic. They must then engage in five sessions of educational remediation with each assigned subject, under the direction of a college pro-

1. Alexander L. Britton is Coordinator of the Special Education Programs at California State College at Long Beach. Robert J. Swan is Coordinator of the Pupil Personnel Services Program and Director of the Educational Psychology Clinic at California State College at Long Beach. fessor, to determine the efficacy of their particular prescription.

Special education trainees are required to observe, through a conventional one-way viewing mirror, psychological and educational evaluations conducted by the school psychologist. They must also perform an educational assessment of each of their assigned children and develop a prescription for the subject; indicating behavioral objectives, strategies, tasks, and evaluative procedures. Psyhcologists' reports; test validity, test results, and implications are discussed during jointly attended case study conferences. Comparisons of trainees' prescriptions are also made. Trainees from both disciplines participate in jointly conducted initial intake parent interviews.

After the initial application of the educational prescription by the school psychologist, the special education trainee assumes the responsibility for the continued remediation regime. The child may be served for the remainder of the semester or the school year; this depends upon the nature of the behavior objectives, their attainment, and/or the specific time prescribed. Although the training program is oriented on a one-to-one ratio, special education trainees are given the opportunity to work with small groups of subjects, dependent upon the nature of the educational prescription suggested for each child. Trainees attend small group and seminar type conferences conducted throughout the year, under the direction of assigned college supervisors.

Plans for the clinic entail the inclusion of pupil personnel trainees in counseling, to work with parents and siblings of children receiving services. Consideration is also being given by the Department of Social Welfare to involve welfare worker trainees in the process of intake interviewing and reporting. School psychology and special education trainees have demonstrated improved proficiencies in the evaluation, assessment, prescription, and educational process during the initial year of the program. They have also demonstrated improvement in interdisciplinary communication, as well as mutual respect.

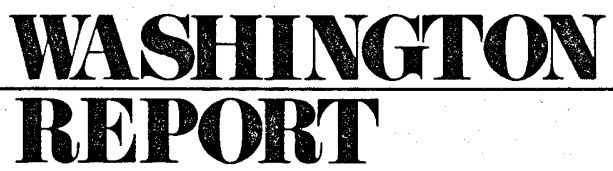

Congress has authorized the establishment of eight regional Centers to serve the deaf-blind child in 40 states throughout the U.S. during Fiscal Year 1969. Plans are 
underway to establish two more Centers in 1970 to serve the remaining states. The Centers are authorized by Public Law 90-247, which amends Title VI, Part C, of the Elementary and Secondary Education Act. Federal funding for Fiscal Year 1969 is $\$ 1,000,000$.

In $1963-65$ an estimated 20,000 to 30,000 children were affected by the rubella (German measles) epidemics which took a heavy toll of birth defects. Many children suffered multiple defects. The Centers were established in the interest of serving the needs of the child who sustained both auditory and visual impairment.

As required by the Act, the Area Centers for Services to Deaf-Blind Children will provide the following services: diagnosis and evaluation; education, adjustment and orientation programs; and thorough consultative services for the parents, teachers, and others concerned with the deaf-blind child.

Research, development, or demonstration of special-ed techniques, in-service training of personnel, and dissemination of materials and information are authorized, though not required, by the Act.

Five of the Centers became operational as of June 1, 1969, and are now providing the services described above. The remaining three will spend their first year developing specific programs for the auditory-visually impaired children in their areas.

The five operational Centers, serving twenty-six states, are located in Talladega, Alabama; Sacramento, California; Watertown, Massachusetts; the Bronx, New York City; and Vancouver, Washington. The three planning Centers, serving fifteen states, are located in Lansing, Michigan; Dallas, Texas; and Denver, Colorado.

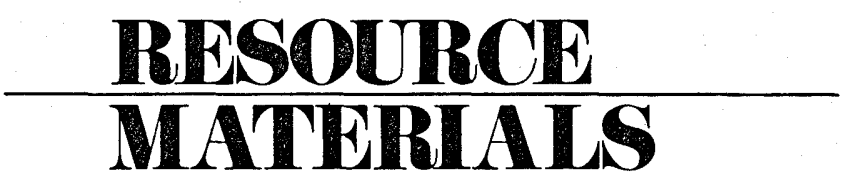

By Linda Smith and Reuben Altman ${ }^{1}$

\section{WINTER HAVEN LIONS RESEARCH FOUNDATION, INC.}

Since 1917 the International Association of Lions Clubs has endeavored to recognize community needs

1. Linda Smith is Curriculum Specialist, Special Education Instructional Materials Center, University of Texas. Reuben Altman is Social Science Research Associate, Rehabilitation Research and Training Center in Mental Retardation, University of Texas. and develop means of meeting them, either through its own effort or in connection with other agencies. The members of Lions Clubs are selected from the community's leading business and professional men, industrialists, farmers, clergymen, educators, merchants and others. Lions International has been instrumental in such projects as building and/or equipping many hospitals, wards and clinics; securing X-ray equipment, eye-examination aparatus, etc.; improving public health departments and furnishing aid for needy persons, orphans, the aged, ill, and blind. Each Lions Club is free to choose the activities in which it will engage, and works on projects which its members believe will best serve the interests of their local community.

The Winter Haven Lions Research Foundation has developed a basic perceptual testing and training program. The materials available to teachers are developed to help kindergarten and first grade pupils achieve their maximum level of learning potential by improving perceptual-motor efficiency. In this achievement program, children manipulate various geometric forms and use templates, as well as engage in rhythmic training, posture exercises, balancing, and coordination drills. The conviction that muscular and motor coordination is related to progress in school achievement, and the belief that perceptual readiness for beginning reading instruction can be improved significantly by specific teacher guided visual-motor training, provided the rationale for the development of this program.

While the Foundation has not as yet reported on the effectiveness of these materials with the mentally retarded, they may prove of merit in the development of reading skills with this population. A brochure listing the Lion's perceptual testing and training materials with their costs as well as informative supplementary materials can be requested from: Winter Haven Lions Research Foundation, Inc., P.O. Box 111, Winter Haven, Florida 33880.

\section{LAWSON BOOK COMPANY}

Recent trends in the education of the mentally retarded have evidenced an increased awareness of the need for practical materials promoting facility in realistic life experiences. Typical arithmetic units stress such functional areas as telling time, making change, and personal accounting, including the management of checking accounts and the reporting of tax information. Similarly, the emphasis in social studies is on developing and maintaining meaningful personal relationships, imbuing a sense of civic responsibility, and imparting the general conceptualization of our social structure incorporating 
the availability of community resources.

The Lawson Book Company has been responsive to this need in the production of materials for both the trainable and educable mentally retarded. The Lawson Training Kit introduces the concepts of money and foods, encourages the mastery of signature writing, and stimulates the ability to recognize and identify survival words such as "danger," "stop," and "hot." Appropriate at a higher level of instruction are a series of workbooks providing exercises relating to newspaper reading, functional economics, introductory government, and physical and mental health.

The Lawson Training Kit sells for $\$ 2.10$ and the workbooks are $\$ 1.60$ per single copy. Both are available at reduced rates for quantity orders. Address inquiries to: Lawson Book Company, 9488 Sara Street, Elk Grove, California 95624.

\section{NATIONAL SAFETY COUNCIL}

The National Safety Council is a non-political organization established in response to the need for a centralized unit of the total safety movement. As part of the Council's effort to develop a sense of individual responsibility and an attitude of mind conducive to the avoidance of accidents, they produce and disseminate needed educational and promotional materials.

The available pedagogical resources are particularly suitable in the curriculum areas of health, safety, and physical education. A wealth of materials may be secured to supplement units in personal protection, first-aid, transportation, and traffic and home saftey. Teachers of the trainable and educable mentally retarded will find materials on the handing and use of manual and power tools, housekeeping and clothing care beneficial in vocational, pre-vocational and home economics training. Included among the types of materials listed in the National Safety Council's Catalog are newsletters, books, posters, banners, decals, slides and a complete driver education course. Film preview and rental information is also offered. Most items are pictured in the catalog and all are accompanied by their purchase price.

Requests for materials and further information should be directed to: School and College Department; National Safety Council; 425 N. Michigan Avenue; Chicago, Illinois 60611.

\section{EXPRESSION COMPANY}

The Expression Company was founded in 1888 by Dr. S. S .Curry who, in 1879, established the Curry School of Expression in Boston. Having lost his speech while a student at Boston University, Dr. Curry undertook thera- peutic lessons from over fifty of the best known authorities in speech work. As a consequence of this experience, he realized the need for vocal training and advocated giving speech education a more prominent place in the curriculum of educational institutions. The first twelve books published by Expression Company, serving as pioneers in the field of speech materials in this country, were authored by Dr. Curry himself. Mindful of this heritage and sense of responsibility, they continue in promoting the knowledge of the causes of speech handicaps and in the publication of materials intended for correction and general improvement of speech.

Included among their speech education and speech therapy materials are a series of pupil workbooks, a practice textbook emphasizing the relationship between speech and reading, and professional texts relating to the area of speech and hearing pathology including $A$ Synthetic Approach to Lip Reading by George S. Haspiel. A collection of books containing choral speaking arrangements for the primary grades through junior high school are also available.

Further information may be obtained from: Expression Company, Educational Publishers, P.O. Box 11, Magnolia, Massachusetts 01930.

The World Mental Health Assembly will be held November 17-21, 1969, at the Shoreham Hotel in Washington, D.C. This conference will serve as the annual meeting for the World Federation for Mental Health and the National Association for Mental Health. For additional information contact Paul V. Lemkau, Chairman, 615 North Wolfe Street, Baltimore, Maryland 21205.

Special Conference on Early Childhood Education, The Jung Hotel, New Orleans, Louisiana, December 9-13, 1969. Write for further information to The Council for Exceptional Children, 1201 Sixteenth Street, N.W., Washington, D. C. 20036.

The International Convention of The Council for Exceptional Children will be held at the Conrad Hilton Hotel, Chicago, Illinois, April 19-25, 1970.

FOCUS ON EXCEPTIONAL CHILDREN back issues are available. Singles copies $80 \phi, 2-9$ copies $70 \phi$, and 10 or more copies $50 \phi$ each. 